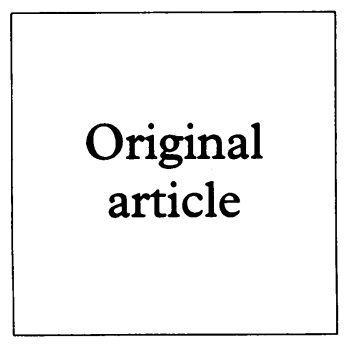

\title{
Markers of sexually transmitted diseases in seminal fluid of male clients of female sex workers
}

\author{
Anne-Marie Worm, Edgar Lauritzen, Inge Panum Jensen, Jørgen Skov Jensen,
} Claus Bohn Christiansen

Objectives: To screen for certain STD markers in a group of male clients of female sex workers. Method: Condoms with seminal fluid were collected at 10 "massage parlours" in Copenhagen. The seminal fluid samples were examined for HIV antibodies, markers of hepatitis B virus (HBV), Chlamydia trachomatis, and Mycoplasma genitalium.

Results: All samples $(n=332)$ were negative for HIV antibodies. Out of 327 samples examined for HBV markers $32(9.8 \%)$ were positive for HBV core antibodies, one of which was also positive for HBV antigen. $C$ trachomatis could be demonstrated in six out of $122(4.9 \%)$ samples and $M$ genitalium in one out of 122 samples.

Conclusions: The finding of a $C$ trachomatis prevalence of $4.9 \%$ is considerable higher than expected in men with a presumed age of 35-55 years. The demonstration of a prevalence of HBV markers of $9.8 \%$ indicates that these clients have an increased risk of HBV infection, a finding that further consolidates the recommendation of $\mathrm{HBV}$ vaccination of sex workers. As shown in this study, STD transmission in commercial sex may also have the client as the source. (Genitourin Med 1997;73:284-287)

Keywords: sex workers; HIV; STD; seminal fluid; condoms

\section{Introduction}

Female sex workers are traditionally defined as women who sell sex for money or other goods. This definition, however, implies at least one other part, the person who provides money in exchange for the sexual service-that is, the client. In order to evaluate the relation between commercial sex and sexually transmitted diseases (STD), prevalences of STD should therefore be measured not only in female sex workers but also in clients.

The theoretical risk of HIV transmission from female sex workers to male clients and further on to the heterosexual community has, during the past decade, led to studies focusing upon STD prevalence and sexual behaviour among Danish sex workers' ${ }^{12}$; however, unselected studies in male clients are difficult to perform.

In order to gather information about STD rates in an unselected group of male clients, condoms with seminal fluid were collected from "massage parlours" in Copenhagen and the contents were screened for certain STD markers.

\section{Material and methods}

Female sex workers from 10 massage parlours in Copenhagen known by the study group from a previous study agreed to participate. ${ }^{2}$ Used condoms were tied routinely with a knot and thrown in a plastic bag under the bed. Plastic bags containing the used condoms with ejaculates from clients who had visited the massage parlours within the previous 24 hours were collected in June 1991, January 1992, and January 1994 at the parlours open on these days. The bags were collected on 2 subsequent days in each period in order to minimise the risk of including samples from the same person twice. All sex workers, ranging from two to four women at each massage parlour, participated.

The seminal fluid samples were diluted with an equal volume of phosphate buffered saline (PBS) and centrifuged for 15 minutes at $2000 \mathrm{~g}$. From the first sampling period in 1991-2, comprising 210 specimens, only the supernatant was kept, whereas both the pellet and the supernatant were kept frozen at $-20^{\circ} \mathrm{C}$ from the second sampling period in 1994, comprising 122 specimens.

All samples were analysed for HIV and for markers of hepatitis B virus (HBV) using the supernatant, whereas only the 122 samples from which the pellets were stored could be used for direct detection of pathogens by the polymerase chain reaction (PCR). Pellets from the centrifuged seminal fluid were resuspended in the remaining supernatant and were processed for PCR by adding $100 \mu \mathrm{l}$ of the material to $300 \mu \mathrm{l}$ of a $20 \%$ w/v suspension of Chelex 100 (Biorad) in TE buffer $(10 \mathrm{mM}$ TRIS $\mathrm{pH} 8.0 ; 1 \mathrm{mM}$ EDTA) and incubating the sample at $95^{\circ} \mathrm{C}$ for 10 minutes. A volume of $25 \mu \mathrm{l}$ of the prepared specimen was used in PCR analysis. 
HIV testing was preferred to hepatitis B core antibody (antiHBc) testing if the amount of material was insufficient.

\section{HIV ANTIBODIES}

The first 210 seminal samples were tested by an in house HIV-1 enzyme linked immunosorbent assay (HIV-1 ELISA), where the working dilution was 1:50 in PBS, and the next 122 samples were tested by the Abbott recombinant HIV-1/HIV-2 third generation enzyme immunoassay (Abbott HIV EIA) after dilution $1: 2$ in PBS. Positive samples were submitted to HIV-1 western blotting. ${ }^{3}$

Paired serum and seminal samples collected from three HIV-1 positive people and from nine HIV negative people served as controls.

By the in house HIV-1 ELISA the positive serum and seminal samples had absorbance values $>2 \cdot 0$ and $>1 \cdot 0$, respectively. The negative serum and seminal samples had mean absorbance values of 0.12 (range $0.03-0.17$ ) and 0.02 (range $0.01-0.07$ ), respectively. The cut off value for seminal fluid was defined at $0 \cdot 15$. The Abbott HIV EIA positive serum and seminal samples had absorbance values $>2 \cdot 0$ whereas the paired negative serum and seminal samples had mean absorbance values of 0.04 (range $0.03-0.11$ ) and 0.06 (range 0.02 $0 \cdot 14$ ), respectively. The cut off value for seminal fluid by this assay was defined at $0 \cdot 15$. Seminal samples with absorbance values above 0.15 were submitted to HIV-1 western blotting.

\section{HEPATITIS B MARKERS}

A total of 327 of the 332 samples (98\%) were tested for antiHBc using a competitive enzyme immunoassay (Corzyme, Abbott Laboratories, USA). The Corzyme is an enzyme immunoassay for the qualitative determination of total antibody to hepatitis B (antiHBc) in human serum or plasma. The Corzyme is not validated for detection of antiHBc in seminal fluid samples.

In order to use seminal fluid samples as a predictor of antiHBc in serum we tested seminal fluid and serum samples from four men positive for antiHBc in serum. Using the cut off value defined by positive and negative controls supplied by the manufacturer all four serum samples were positive, but all four seminal samples were negative. By titration of the serum samples in order to estimate the titre, two samples had a very high titre of antiHBc, whereas two turned negative after a dilution of 1:5. The seminal samples corresponding to the two high titre serum samples showed an antiHBc optical density (OD) value between the cut off value and the negative control value, whereas the antiHBc OD value of the seminal samples corresponding to the two low titre serum samples were close to the negative control OD value. We defined a new antiHBc cut off for seminal fluid samples as the cut off value (for serum samples) $\times 1.95$.

All seminal fluid samples classified as positive for antiHBc according to the new cut off value were tested for hepatitis B surface antigen (HBsAg) by an enzyme immunoassay (Auszyme, Abbott Laboratories, USA).

\section{CHLAMYDIA TRACHOMATIS}

$C$ trachomatis was detected by amplification of the cryptic plasmid using primers CP24/ CP27. ${ }^{4}$ Each reaction tube received an internal processing control containing the primer binding sites in order to assure the validity of negative results. All positive results were confirmed by amplification of the $C$ trachomatis $16 \mathrm{~S}$ rRNA gene using primers $1 \mathrm{~A} / 1 \mathrm{~B} .{ }^{5}$

This PCR method was previously validated against $C$ trachomatis culture by investigating 100 seminal samples from men with infertility where it was found to detect $3 / 3$ culture positive plus one additional PCR positive culture negative. The latter specimen was positive also in another laboratory using another PCR technique (unpublished results).

\section{MYCOPLASMA GENITALIUM}

$M$ genitalium was detected by amplification of a part of the main adhesion protein gene MgPa. ${ }^{6}$ Positive results were confirmed by amplification of the $M$ genitalium $16 \mathrm{~S}$ rRNA gene (unpublished results). The method has not been validated against culture since $M$ genitalium is extremely difficult to isolate.

\section{Results}

Altogether 332 condoms were collected, 210 condoms in $1991 / 1992$ and 122 condoms in 1994.

\section{HIV ANTIBODIES}

All seminal samples from the condoms were tested for HIV antibodies and all were negative.

\section{HBV MARKERS}

A total of 327 seminal samples were examined for antiHBc, of which $32(9 \cdot 8 \%)$ were positive. Among the 32 antiHBc positive samples, one was positive and 31 were negative for $\mathrm{HBsAg}$.

\section{CHLAMYDIA TRACHOMATIS}

A total of six out of 122 seminal samples (4.9\%) were confirmed PCR positive for $C$ trachomatis. Only one of the samples contained a significant amount of PCR inhibitors necessitating a fivefold dilution before a valid negative result could be obtained.

\section{MYCOPLASMA GENITALIUM}

$M$ genitalium was only detected in one out of 122 seminal samples. This sample was $C$ trachomatis negative.

\section{Discussion}

In Denmark, with a population of five million inhabitants, an estimated number of at least 5000 sexual transactions involving about 1500 female sex workers take place every day, the majority in massage parlours. ${ }^{7}$ According to the female sex workers, male clients are mainly 35-55 years old, most of them are married or cohabiting, representing a broad spectrum of the society. ${ }^{7}$ In representative samples of Danish men, 13\%-14\% have had sexual contact with sex workers once or more in their 
life, ${ }^{89}$ and $48 \%$ of these men have had a history of one or more STD, ${ }^{8}$ figures that are in line with those from other European countries. ${ }^{10}$

Behavioural information about female sex workers and clients that are based upon studies among STD clinic attenders may be biased, as STD clinic attenders are selected, may have a higher refusal rate when participating in behaviour studies, and may not be discovered as female sex workers or clients if they do not want to identify themselves as such. When comparing clients recruited at an STD clinic with those recruited outside, a history of STD was much more frequently reported among the STD clinic sample in a study from Glasgow and a study from Amsterdam, ${ }^{11} 12$ and clients with relatively high risk behaviour were strongly represented among the STD clinic sample in one of these studies. ${ }^{12}$

Among STD clinic attenders in Denmark, $17 \%$ of the heterosexual men reported to have had sex with a female sex worker, the proportion increased with reported number of sex partners. ${ }^{13}$ From the same study, which is an ongoing surveillance study, chlamydial infection was present in $6.1 \%$ of those with a history of ever being a client of a female sex worker but, again, this figure gives no information about the number of clients who are infected when the sexual transaction takes place.

Information about STD prevalence among Danish sex workers is from recent studies based upon interview. ${ }^{2}$ In one of these studies, ${ }^{2} 111$ out of 253 female sex workers reported STD examination within the past year resulting in the finding of $C$ trachomatis in $8 \%, M$ genitalium in $4 \%$, and hepatitis B markers in $1 \%$. The frequency of STD (other than HIV) among these sex workers was correlated with the number of non-paying sexual partners and with the inconsistency in condom use. ${ }^{2}$ In contrast, HIV infection is closely related to drug use. ${ }^{14} \mathrm{HIV}$ infection has not been found in non-drug using sex workers in Denmark, ${ }^{12}$ and in only a few cases from other European countries. ${ }^{1215}$

Studies focusing upon HIV prevalence among male clients of female sex workers have recruited participants from STD clinics and by advertising. ${ }^{121617} \mathrm{~A}$ few cases have been positive but as the clients were not randomly selected they can only give very limited information about the risk of HIV transmission from the male client to the female sex worker. The participants in our study, who were all HIV negative, were selected as to the type of sex workers they visited, but were otherwise unselected, as the sample of sex workers routinely refused clients who would not use a condom.

The risk of HIV transmission by non-drug related sex workers seems, therefore, to be very low in many European countries. The advantage, however, is that it has given rise to a very high level of condom use. ${ }^{215}$ Consequently, nowadays, female sex workers rarely transmit HIV or STD. ${ }^{18}$

Men aged 20-29 years account for $65 \%$ of all laboratory reported male chlamydial cases in Denmark, those aged 30 years or more account for $19 \%$, and those aged 40 years or more account for only $5 \% .{ }^{19}$ Studies of the prevalence of chlamydial infections in unselected groups of Danish men, have been performed among those aged 17-26 years already in, or liable for, military service, where $5.7 \%$ and $7.9 \%$ respectively had urethral chlamydial infections. ${ }^{2021}$

The prevalence of chlamydial infections in an unselected group of men aged between 35 and 55 years, which is the presumed age of the clients in this study, is not known, but if this age group accounts for $10-15 \%$ of all chlamydial infections a prevalence of $0.6-1 \cdot 2 \%$ should be expected, based upon the reported prevalence among younger men. ${ }^{2021}$ The finding that $C$ trachomatis could be demonstrated in $4.9 \%$ of the seminal samples in this study, therefore, suggests that these men had a four to eight times higher rate of infection than the general population based on the above calculations. Previous studies were based on urine sampling and enzyme immunoassays, ${ }^{2021}$ whereas this study used the more sensitive PCR technique, ${ }^{52}$ a fact that may overestimate the difference between the expected and the observed prevalence. Furthermore, the fact that the rather informal sampling method could have caused some sample to sample carryover cannot be totally excluded. However, since we did not find more than one $M$ genital ium PCR positive specimen this threat to the validity of the results may be minor.

$M$ genitalium has been found in men with non-gonococcal, chlamydia negative urethritis, and a causal connection has been suggested. ${ }^{2324}$ The prevalence of this microorganism in asymptomatic men has, however, not been elucidated, so it is difficult to relate the finding of this micro-organism in one of the samples to other studies.

The presence of antiHBc together with a negative test for HBsAg is a marker of a past but now non-transmissible infection. The finding of an antiHBc prevalence of $9.8 \%$ may be considerably underestimated as antiHBc could only be detected in the seminal samples from two controls with high antiHBc serum titres, whereas it was undetectable in two controls with low serum titres. Denmark is a low endemic area for HBV. In spite of this, the measured prevalence was at least twice as high as that found in Danish blood donors, in the same range as is found among heterosexual STD clinic attenders born in Denmark, but lower if the STD clinic attenders were from intermediate and high endemic areas. ${ }^{25}$ Therefore, it seems reasonable to conclude that the clients from whom the seminal samples in this study originated had an increased risk of being HBV infected, and so female sex workers should consider $H B V$ vaccination.

HBV is the only STD for which a protective vaccine has been developed, whereas the only protection against other STDs is the consistent use of condoms.

It is well documented that intact latex condoms provide a continuous mechanical barrier 
to both bacterial and viral (including HIV) micro-organisms that are sexually transmissible, and that condoms are unlikely to break or slip during proper use, with a breakage rate of $2 \%$ for vaginal or anal intercourse and a complete slippage off the penis rate of less than $1 \%{ }^{26}$ Higher condom failure rates have, however, been reported. ${ }^{11} 17$ Though a large percentage of sex workers and clients reported condom breakage or slippage in one study, the frequency of occurrence was low and attributed to the skill with which most sex workers handle condoms. ${ }^{27}$

The level of condom use with clients is very high among sex workers in Denmark as in other European countries, ${ }^{12}{ }^{16}$ but much lower with casual and especially with regular nonpaying partners, a pattern also found among clients. ${ }^{17}$ Thus, it seems reasonable to conclude that the risk of acquiring or transmitting an STD in Denmark may be lower when money is involved in a sexual service compared with sexual contacts between casual and/or regular non-paying partners. However, when there is condom failure clients are a major potential source of STD infection in female sex workers.

1 Krogsgaard K, Gluud C, Pedersen C, Nielsen JO, Juhl E, Gerstoft $\mathrm{J}$, et al. Widespread use of condoms and low prevalence of sexually transmitted diseases in Danish non-drug addict commercial sex workers. $B M F 1986$ 293:1473-4

2 Alary M, Worm AM, Kvinesdal B. Risk behaviours for HIV infection and sexually transmitted diseases among female sex workers from Copenhagen. Int $₹$ STD AIDS 1994; 5:365-7.

3 Lauritsen E, Lindhardt BØ. Antibodies against human immunodeficiency virus (HIV) detected by immunoblotting. In: Bjerrum OJ, Heegaard NHH, eds. Handbook of immunoblotting of proteins. Boca Raton, FL: CRC Press, 1989.

4 Loeffelholz MJ, Lewinski CA, Silver SR, Purohit AP, Herman SA, Buonagurio DA, Dragon EA. Detection of Chlamydia trachomatis in endocervical specimens by polymerase chain reaction. $f$ Clin Microbiol 1992;30 2847-51.

5 Pollard DR, Tyler SD, Ng CW, Rozee KR. A polymerase chain reaction (PCR) protocol for the specific detection of Chlamydia spp. Mol Cell Probes 1989;3:383-9.

6 Jensen JS, Uldum SA, Sondergard-Andersen J, Vuust J, Lind K. Polymerase chain reaction for detection of Mycoplasma genitalium in clinical samples. $¥$ Clin Microbiol 1991;29:46-50.

7 Jensen TB, Koch I, Kongstad A, Dahl A. Prostitution in Denmark. Socialforskningsinstituttet, Report 90:8, Copenhagen 1990

8 Schmidt KW, Krasnik A, Brendstrup E, Zoffmann $\mathrm{H}$ Larsen S. Occurrence of sexual behaviour related to the risk of HIV-infection. A survey among Danish men 16-55 years of age. Dan Med Bull 1989;36:84-8.

9 Melbye M, Biggar RJ. Interactions between persons at risk for AIDS and the general population in Denmark. $A m \mathcal{F}$ Epidemiol 1992;15;135:593-602.

10 de Graaf R. Prostitutes and their clients; sexual networks and determinants of condom use. Thesis, University of Amsterdam, 1995.

11 Barnard MA, McKeganey NP, Leyland AH. Risk behaviours among male clients of female prostitutes. $B M \mathcal{F}$ 10urs among male

12 van Haastrecht HJ, Fennema JS, Coutinho RA, van der Helm TC, Kint JA, van den Hoek JA. HIV prevalence and risk behaviour among prostitutes and clients in Amsterdam: migrants at increased risk for HIV infection. Genitourin Med 1993;69:251-6.

13 Smith E, Worm AM, Jepsen LV, Larsen J, Brandrup F Veien N, Andersen BL. Patterns and trends of sexua behaviour, HIV testing and HIV prevalence among all sexually transmitted disease clinic attenders in Denmark. Sex Transm Dis 1994;21:97-102

14 van den Hoek JA, Coutinho RA, van Haastrecht HJ, van Zadelhoff AW, Goudsmit J. Prevalence and risk factors of HIV infections among drug users and drug-using prostitutes in Amsterdam. AIDS 1988;2:55-60.

15 European Working Group on HIV Infection in female prostitutes. HIV infection in European female sex workers: epidemiological link with use of petroleum-based lubricants. AIDS 1993;7:401-8.

16 Day S, Ward H, Perrotta L. Prostitution and risk of HIV male partners of female prostitutes. BMF 1993;307: 359-61.

17 Fennema JS, van Ameijden EJ, Coutinho RA, van Doornum GJ, Henquet CJ, van den Hoek JA. HIV prevalence among clients attending a sexually transmitted diseases clinic in Amsterdam: the potential risk for heterosexual transmission. Genitourin Med 1993;69:23-8.

18 Darrow WW. Prostitution and sexually transmitted diseases. In: Holmes KK, Maardh P, Sparling PF, et al, eds. Sexually transmitted diseases. New York: McGraw-Hill, Sexually

19 Bollerup Ac, Larsen So. Klamydia 1988-1992. Epi-Nyt 1993;21.

20 Søgaard P, Møller BR, Thorsen P, Nissen LR, Pedersen S, Kargo JC, Jensen AM. Prevalence of Chlamydia trachomatis among young men and women in military service. Comparison of urethral swab with a urine sample. Ugeskr Lager 1996;158:759-63.

21 Jensen IP. A comparison of urine sample to urethral swab for detection of Chlamydia trachomatis in asymptomatic young men using two enzyme immunoassays. Sex Transm Dis 1992;19:165-9.

22 van den Brule AJ, Hemrika DJ, Walboomers JM, Raaphorst P, van Amstel N, Bleker OP, Meijer CJ. Detection of Chlamydia trachomatis in semen of artificial insemination donors by the polymerase chain reaction Fertil Steril 1993;59:1098-104.

23 Jensen JS, Orsum R, Dohn B, Uldum S, Worm AM, Lind K. Mycoplasma genitalium: a cause of male urethritis? Genitourin Med 1993;69:265-9.

24 Horner PJ, Gilroy CB, Thomas BJ, Naidoo RO, TaylorRobinson D. Association of Mycoplasma genitalium with acute non-gonococcal urethritis Lancet 1993;342.582-5.

25 Kvinesdal BB, Worm AM, Gottschau A. Risk factors for hepatitis B virus infection in heterosexuals attending a venereal disease clinic in Copenhagen. Scand $¥$ Infect Dis venereal disease

26 Update: barrier protection against HIV infection and other sexually transmitted diseases. MMWR 1993;42:589-91, 597.

27 de Graaf R, Vanwesenbeeck I, van Zessen G, Straver CJ, Visser JH. The effectiveness of condom use in heterosexual prostitution in the Netherlands. AIDS 1993;7:265-9. 